\title{
High-Intensity Interval Training and Continuous Training with Intermittent Calorie Restriction in Overweight Women: Effect on the Inflammation and Lipid Profile*
}

\author{
Vahid SARI-SARRAF ${ }^{1}$ D, Nazila PARNIAN-KHAJEHDIZAJ ${ }^{\dagger 1}$ (D), Ramin AMIRSASAN ${ }^{1}$ (D)
}

${ }^{1}$ Faculty of Physical Education and Sport Sciences, Tabriz University, Tabriz, Iran

Original Article

Received: 05.11.2020
Accepted: 30.11 .2020
DOI: $10.25307 /$ jssr.819590

Online Publishing: 31.12 .2020

\begin{abstract}
The purpose of the study was to explore the combination of ICR with High Intensity Interval Training (HIIT) or continuous training over a 8-weeks on inflammatory and lipid profile indexes in overweight women. In the current quasi-experimental study, 36 overweight and obese women were randomly grouped in four groups $(\mathrm{n}=9$ /group) for an additional 8 weeks as follows: 1) intermittent caloric restriction ( $\mathrm{N}=9)$ ( $20 \%$ lower energy intake), 2) continuous training+ICR ( $\mathrm{N}=11)(20 \%$ energy deficit created by $10 \% \mathrm{CR}$ and 10\% EE through CT), 3) High-Intensity Interval Training+ICR (N=9) (20\% energy deficit created by $10 \% \mathrm{CR}$ and $10 \%$ EE through HIIT) and 4) control (N=9) (remain on diet). Blood samples were collected to measure the inflammatory indexes (the number of environmental blood leukocytes and C-reactive protein) as well as lipid profile (total cholesterol, triglyceride, HDL and LDL). Data were analyzed using Shapiro-Wilk tests to investigate the natural distribution of the data; repetitive variance was also used to investigate the mean difference between phases and the interactive effect between phases and groups; Bonferroni post-hoc test was also used for comparing intergroup changes in the significance level of $\alpha<0.05$. Eight weeks of HIIT and continuous training with ICR led to significant changes in all indexes including lipid profile (HDL, LDL, total cholesterol, triglyceride), $\mathrm{VO}_{2 \max }, \mathrm{CRP}$ compared to the pre-test phase. Moreover, there was a significant intergroup difference in the indexes of lipid profile and CRP among control group and ICR, HIIT+ICR and ICR+ continuous groups, lastly, there was also an intergroup cholesterol index (ICR) and HIIT+ICR and ICR+continuous groups $(\mathrm{p}<0.05)$. Regarding $\mathrm{VO}_{2 \max }$, there was a significant intergroup difference between the control group and HIIT+ICR and ICR+ continuous groups $(\mathrm{p}<0.05)$. Due to the marked and noticeable effects of eight weeks of HIIT and continuous training along with ICR on inflammatory and lipid profile indexes in overweight women, it can be concluded that the combination of these interventions can be effective in controlling the weight and obesity.
\end{abstract}

Keywords: HIIT, Continuous training, Intermittent calorie restriction, Inflammation, Lipid profile, Overweight women.

${ }^{*}$ This article is taken from the master thesis of Nazila PARNIAN-KHAJEHDIZAJ, a graduate student of the Faculty of Physical Education and Sport Sciences, University of Tabriz.

†Corresponding Author: Nazila PARNIAN-KHAJEHDIZAJ, E-mail: nazilaparnian70@ gmail.com. 
Sari-Sarraf, V., Parnian-Khajehdizaj, N., \& Amirsasan, R. (2020). High-intensity interval training and continuous training with intermittent calorie restriction in overweight women: Effect on the inflammation and lipid profile. Spor Bilimleri Araştırmaları Dergisi, 5(2), 230-246.

\section{INTRODUCTION}

Obesity and overweightness are a mild general inflammatory status, which are prevalent all over the world nowadays and can increase the risk of cardiovascular diseases, type II diabetes, cognition disorders and finally death through various mechanisms (Barranco et al., 2012). Inflammation in blood lipid profile is one of the consequences resulting from overweightness and obesity, which is directly linked to many other diseases such as cancer (breast, colorectal, lung) and diabetes as is validated by many studies (Dossus et al., 2010; Janghorbani, 2007).

Exercise helps in preventing coronary disease through changing the inflammation. The influence of exercise on C-reactive protein (CRP) is a new subject which may affect resting CRP, whose low scopes are used for predicting cardiovascular diseases. Calorie restriction with or without exercise significantly reduces all indexes of inflammation, CRP and IL-6. Aerobic trainings along with weight loss significantly reduces cholesterol, low-density lipoprotein (LDL) and diastolic blood pressure as well as improving physical fitness (Pihl et al., 2003; Rawson et al., 2003).

Many efforts have been made in order to identify and access the effective approaches for preventing problems related to obesity and extending lifespans (Gist et al., 2014). Among various approaches, regular physical activity and calorie restriction, not only are among effective weight controlling methods, but also reduce the risk of having cardiovascular diseases and chronic metabolism diseases (Campbell, 2007). However, calorie restriction is applied in two forms: chronic (CCR) and intermittent (ICR). The difference between the two methods lies in the fact that the ICR uses a reduction in the frequency of meals to reduce calorie intake, while the CCR uses a reduction in the amount of intake received at all meals; Therefore, the pressure of metabolism and consequently feelings of physical and mental discomfort are infrequent for people (Johnson et al., 2009).

Therefore, researchers proposed that adding exercise to the calorie restriction program would reduce inflammatory signifiers and its resulting probable negative consequences. In this regard, Imayama et al., (2012) investigated the effect of applying one-year calorie restriction (with the aim of reducing the weight for 10 percent in a year) along with aerobic trainings (having moderate to severe trainings for 225 minutes in a week) and reported that calorie restriction diet with aerobic trainings reduced inflammation indexes in menopause overweight women (Imayama et al., 2012). Allen et al., (2017) compared the effect of nine weeks of high-intensity aerobic training ( doing speed trainings for 30s on a Ergometer, having 4-5min inactive recovery between each phase) and continuous long term speed exercise (speed exercise for $10 \mathrm{~s}$, 2-3min of light exercise between each phase) on inflammation systematic indexes among inactive elderly men and women (49.2 \pm 6.1 years old) and noticed that in both kinds of exercising, $\mathrm{VO}_{2 \max }$ significantly increased; however, the waist size significantly reduced in High Intensity Interval Training (HIIT) group. Moreover, CRP and TNF-a changes in both exercise groups didn`t depict significant differences with control group (Allen et al., 2016).

Davis et al. (2017) investigated the effect of HIIT and MIT along with CR (25\%) on the glucose and fat metabolism of obese rats (aging 32 weeks). In this study, rats were placed in four groups including (25\% calorie restriction), (12.5\% calorie restriction+ $12.5 \%$ HIIT) and $(12.5 \%$ 
Sari-Sarraf, V., Parnian-Khajehdizaj, N., \& Amirsasan, R. (2020). High-intensity interval training and continuous training with intermittent calorie restriction in overweight women: Effect on the inflammation and lipid profile. Spor Bilimleri Araştırmaları Dergisi, 5(2), 230-246.

calorie restriction $+12.5 \%$ MIT). These researchers concluded that the intensity of training did not increase fat tissues' exothermic signifiers, while in the presence of CR, significant reductions in the obesity and improvement of energy metabolism took place (Davis., 2017).

The number of blood leukocytes and neutrophils are appropriate indexes for evaluating the inflammation and the increase of these indexes` density has a positive correlation with the risk of having cancer and death in menopause women (Margolis, 2007). However, little is known about the effects of weight loss through calorie restriction and training on the number of leukocytes, neutrophils and lipid profile (Brown et al., 2015; Weiss et al., 2016). Therefore, this assumption seems logical that inclusion of exercising practices in weight loss programs leads to the improvement and adjustment of the effects of calorie restriction on inflammation, lipid profile, BMI and metabolism complication indexes. In this regard, several clinical trials have tested this assumption in a certain way and metabolic responses have been compared with diet restriction interventions and exercise therapy (Davis et al., 2017).

Recently, HIIT has been introduced as an efficient and effective training intervention that can have health profits similar to moderate aerobic continuous training (Gibala et al., 2012). Despite the fact that the overall volume of training in HIIT is less than aerobic continuous training, its positive effect on the inflammation, lipid profile, glycemic control and sensitivity to insulin is similar or better than continuous aerobic trainings (Perry et al., 2008). However, considering the limited and controversial results concerning the comparison of the effect of HIIT and continuous aerobic training as well as the synergistic effect of calorie restriction in combination with such kind of trainings and not having access to comprehensive studies on elderly and inactive women, this question was posed whether the combination of these training activities in conjunction with calorie restriction can reduce the undesired effects of calorie restriction. Therefore, the current study aimed at determining the effect of eight weeks of intermittent calorie restriction combined with HIIT or continuous training on inflammation and lipid profile indexes of overweight women; to this end, a quasi-experimental research design with four groups were used to whom repetitive measurements were applied.

\section{METHOD}

\section{Participants}

The current quasi-experimental research had a pretest-posttest design, which was administered using field and laboratory methods. This research investigated the effect of eighth weeks of HIIT, continuous training and calorie restriction (independent variables) in lipid profile and inflammation indexes. Forty-four people were recruited through advertising, sports associations and social media. Statistical population of the current study included all overweight and obese women BMI (between $25-30 \mathrm{~kg} / \mathrm{m}^{2}$ ), fat percentage (BF; between 30-35 $\%$ ) of Tabriz whose age ranged between 35 and 55 years (figure 1). After providing written informed consent and completing the medical history visit, all subjects performed a stress test under the supervision of a cardiologist to evaluate any cardiac abnormalities that would prevent their participation in the study. The studied sample number for each four group had been estimated to be 9 individuals (overall, 36 individuals participated) using the (https://www.graphpad.com/quickcalcs/randomize1.cfm) by GraphPadSoftware, SanDiego, California. 
Sari-Sarraf, V., Parnian-Khajehdizaj, N., \& Amirsasan, R. (2020). High-intensity interval training and continuous training with intermittent calorie restriction in overweight women: Effect on the inflammation and lipid profile. Spor Bilimleri Araştırmaları Dergisi, 5(2), 230-246.

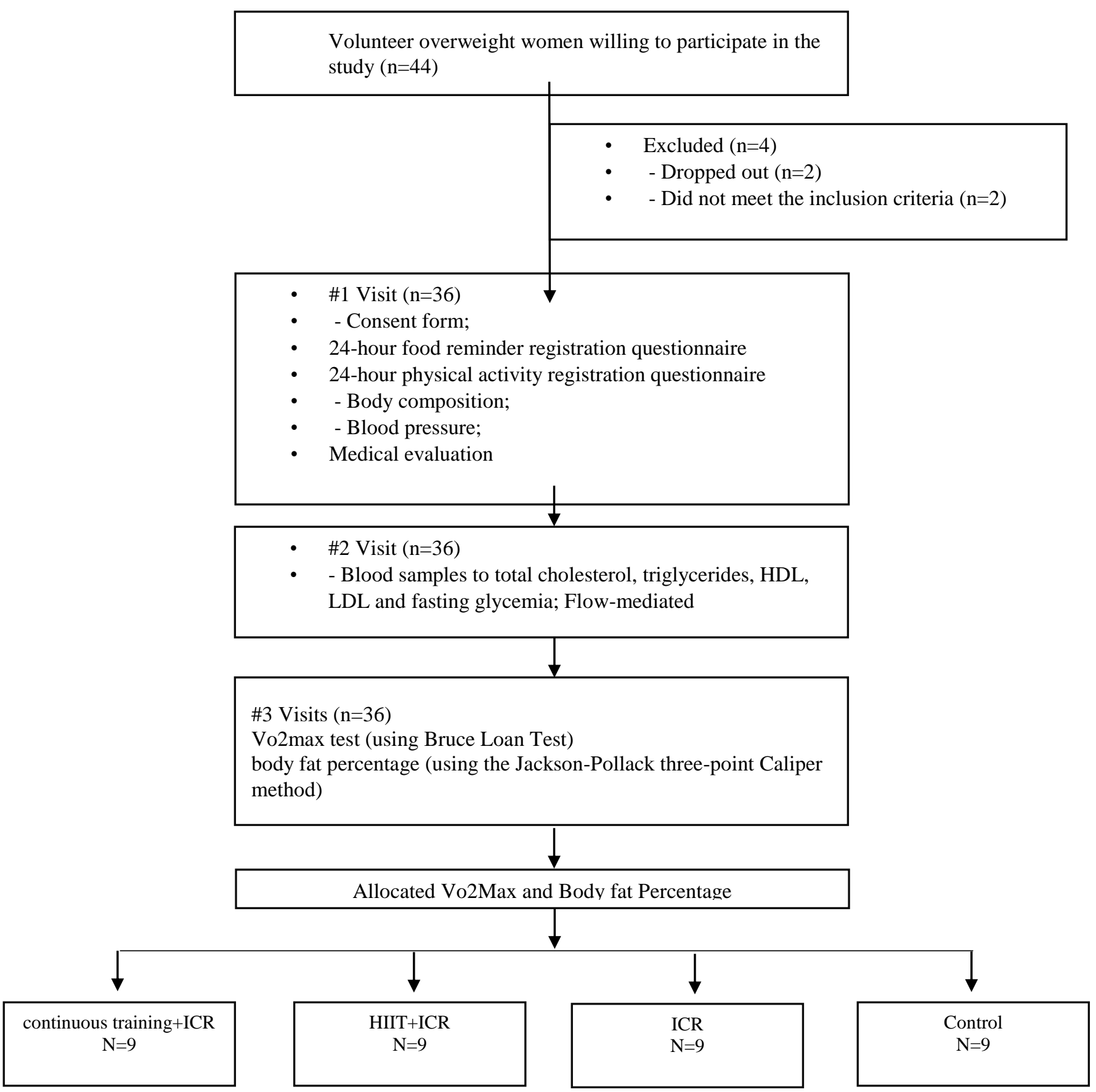

Figure 1. Study design according CONSORT Statement. 
Sari-Sarraf, V., Parnian-Khajehdizaj, N., \& Amirsasan, R. (2020). High-intensity interval training and continuous training with intermittent calorie restriction in overweight women: Effect on the inflammation and lipid profile. Spor Bilimleri Araştırmaları Dergisi, 5(2), 230-246.

\section{Training protocol}

Each session of HIIT included three parts of warm-up, main part of training and cool-down. In these sessions, Gibala et al. (2012)`s adapted protocol was utilized (Table 1).

Table 1. High intensity interval training protocol

\begin{tabular}{cccccc}
\hline Week & $\begin{array}{c}\text { The number of } \\
\text { turns running }\end{array}$ & $\begin{array}{c}\text { Running } \\
\text { time each } \\
\text { step (s) }\end{array}$ & $\begin{array}{c}\text { Rest period } \\
\text { (Minutes: seconds) }\end{array}$ & $\begin{array}{c}\text { Total duration } \\
\text { (Second) }\end{array}$ & $\begin{array}{c}\text { Heart rate range } \\
\text { (Maximum heart } \\
\text { rate percentage) }\end{array}$ \\
\hline 1 & $6-4$ & $15 \mathrm{sec}$ & $3 \mathrm{~min}$ & $90 \mathrm{sec}$ & $85-75$ \\
2 & $6-4$ & $20 \mathrm{sec}$ & $3 \mathrm{~min}$ and $15 \mathrm{sec}$ & $120 \mathrm{sec}$ & $85-75$ \\
3 & $6-4$ & $20 \mathrm{sec}$ & $3 \mathrm{~min}$ & $120 \mathrm{sec}$ & $90-80$ \\
4 & $8-6$ & $15 \mathrm{sec}$ & $3 \mathrm{~min}$ & $120 \mathrm{sec}$ & $90-80$ \\
5 & $8-6$ & $20 \mathrm{sec}$ & 3 min and 30 sec & $160 \mathrm{sec}$ & $90-80$ \\
6 & $8-6$ & $25 \mathrm{sec}$ & $4 \mathrm{~min}$ & $200 \mathrm{sec}$ & $90-80$ \\
7 & $8-6$ & $30 \mathrm{sec}$ & $4 \mathrm{~min}$ & $240 \mathrm{sec}$ & $90-80$ \\
8 & $8-6$ & $30 \mathrm{sec}$ & 3 min and 45 sec & $240 \mathrm{sec}$ & $90-80$ \\
\hline
\end{tabular}

HIIT: High-Intensity Interval Training

Before starting the main training protocol, to increase participants` willingness to be present in the trainings, two weeks of moderate intensity aerobic trainings were administered. Participants held continuous training sessions for eight weeks, three sessions each week for 60 minutes during 9 a.m. to 11 a.m., which included three phases of warm-up, main training and cooldown. The main training part started with 30min fast walking in the first week having $60-65 \%$ of saved heart beat that subsequently increased to $40 \mathrm{~min}$ fast walking with $65-75 \%$ saved heart beat in the eighth week. It should be noted that both types of continuous and intermittent trainings were homogenized in terms of calorie $(19,34)$, personal characteristics such as age, menopause status, environmental factors (temperature, the hygiene of the exercising place) and the intensity of performed trainings. To control the intensity of trainings, carotid heart beats of the neck and Borg`s rate of perceived effort were employed. Therefore, before starting the trainings, 60, 65, 70, 75, 80, 85 and 90 percentages as well as Karronen`s heart beat percentage were determined for each participant. To ensure the accuracy of heartbeat measurement, the number of reported heart beats by the subject while doing activities was compared with the intensities of low, moderate and high measured beats using Polar device.

The equation of the intensity of done trainings (Housh, 2017):

$\mathrm{HR}_{\max }=208.5-(0.8 \times$ age $)$

Exercise $\mathrm{HR}=\%$ of target intensity $\left(\mathrm{HR}_{\max }-\mathrm{HR}_{\text {rest }}\right) \mathrm{HR}_{\text {rest }}$

\section{Calorie Restriction}

Participants were selected based on BMI, fat percentage and after confirming their suitability based on $\mathrm{VO}_{2 \max }$, and fat percentage, they were placed in four groups of moderate ICR (20\%), the combination of HIIT and ICR (10\% increase in energy cost due to training and $10 \%$ ICR), the combination of moderate continuous training and ICR $(10 \%$ calorie restriction due to exercising and 10\% ICR) and control. Then, to calculate the amount of received calorie reduction, each subject first filled out the form and $24 \mathrm{~h}$ diet reminder for 3 days $(2$ common days and 1 holiday). In order to calculate and estimate the amount of daily energy cost, subjects filled physical activity forms for 3 days (Gibson et al.,2018). Having calculated the amount of subjects`received energy in ICR for $20 \%$, they received calorie reduced diet consisting of $10 \%$ of fat, $5 \%$ of carbohydrate and $5 \%$ of protein. The amount of received energy in the subjects of exercising+ ICR group (both type of exercising) decreased to $10 \%$ of received calorie which 
Sari-Sarraf, V., Parnian-Khajehdizaj, N., \& Amirsasan, R. (2020). High-intensity interval training and continuous training with intermittent calorie restriction in overweight women: Effect on the inflammation and lipid profile. Spor Bilimleri Araştırmaları Dergisi, 5(2), 230-246.

consisted of $5 \%$ fat, $2.5 \%$ carbohydrate and $2.5 \%$ protein and doing physical activities (energetic equation 10\%) was added to their daily energy expenditure. In order to isocalorize the reduction rate of the received calorie through dieting and to increase the energy cost via increasing the physical activity, metabolism equations, including the amount of energy cost of physical activity and the amount of increasing required energy cost, were used for increasing the energy cost to a certain level. Using metabolism equations and estimating the amount of received calorie, the overall and reduction amount of the received calorie was calculated to attain the considered amount; this was accomplished through calculating the energy content of each received food (Astorino et al., 2017; Ferguson., 2014; Gibson et al., 2018; Housh et al., 2017; Zhang, 2017).

\section{Measurements}

Before and after the training period, all subjects participated in the same testing visit. All subjects were instructed to be fast and no to perform any exercise for $8 \mathrm{~h}$ before the testing. On the test day, participants arrived at the laboratory around 8:00 am. Height and body weight were measured with a digital electronic scale (Body scale Height and Weight scale BS 286), and body composition was assessed using Body composition BC 360. Excessive aerobic power or oxygen consumption was performed using the Bruce Loan Test (using a single-treadmill treadmill made in Italy). Finally, the skin fold thickening method was used in three areas (triple head, thigh, and supraspinatus) using the Jackson-Pollack three-point caliper method to measure fat percentage (Jackson \& Pollock, 1985). Moreover, anthropometric measurements were carried out two weeks before starting the training process and at the end of final session.

\section{Blood biochemistry}

Blood samples were collected $48 \mathrm{~h}$ before starting the training protocol and calorie restriction and $24 \mathrm{~h}$ after the last session of training and calorie restriction to measure the number of environmental blood leukocytes and CRP and total cholesterol, triglyceride, HDL, LDL. Blood samples were taken from antecubital vein and collected into BD Vacutainers Tubes (SST ${ }^{\mathrm{TM}}$ II Advance, REF 367953). After this phase, samples were centrifuged (4000 RPM at $4{ }^{\circ} \mathrm{C}$ using centrifuge J6-MC by Beckman). The amount of TG, TC and HDL were measured using lipid measurement kit (Pars Azmun Company) through spectrophotometry method of auto analyzer device. The amount of LDL was calculated through TG, TC and HDL amount as well as Friedewald formula (Friedewald et al.,1972).

\section{Ethical Approval:}

Having been confirmed by ethical committee of Tabriz University of Medical Sciences with the code of Ir.TBZMED.REC.1397.654, in 2018, the subjects participated in an explanatory class related to the test and they were educated regarding all important issues of the test.

\section{Statistical analysis}

Data is expressed as SD. Statistical analysis was performed using SPSS / PASW software, version 22, Windows and Excel 2010 at a significant level $\alpha<0.05$. Through the Shapiro-Wilk $\mathrm{W}$ test, we assessed the normality between the groups. Intragroup effects were performed using one-way analysis of variance. Changes in each indicator were evaluated at different stages of measurement with repeated ANOVA measurements $(2 \times 4)$. If there is a difference between the groups studied, the Bonferoni statistical test is used to determine the data (mean and standard deviation). 
Sari-Sarraf, V., Parnian-Khajehdizaj, N., \& Amirsasan, R. (2020). High-intensity interval training and continuous training with intermittent calorie restriction in overweight women: Effect on the inflammation and lipid profile. Spor Bilimleri Araştırmaları Dergisi, 5(2), 230-246.

\section{FINDINGS}

36 overweight women (aged 35-55) in Tabriz participated in this study. Average and standard deviation of demographic characteristics (age, weight, lean weight, body fat, body mass index, basal metabolic rate, and total energy expenditure and calorie intake) of the subjects are presented separately in (Table 2).

Table 2. Descriptive data subjects (mean \pm SD)

\begin{tabular}{|c|c|c|c|}
\hline Variables & Groups & $\begin{array}{c}\text { Mean } \pm \text { standard } \\
\text { deviation (pre-test) }\end{array}$ & $\begin{array}{c}\text { Mean } \pm \text { standard } \\
\text { deviation (post-test) }\end{array}$ \\
\hline \multirow{4}{*}{$\begin{array}{c}\text { Age } \\
\text { (Year) }\end{array}$} & $\mathrm{CON}$ & \multicolumn{2}{|c|}{$41.33 \pm 6.71$} \\
\hline & ICR & \multicolumn{2}{|c|}{$41.2 \pm 5.51$} \\
\hline & HIIT+ICR & \multicolumn{2}{|c|}{$41.72 \pm 4.81$} \\
\hline & $\mathrm{CONT}+\mathrm{ICR}$ & \multicolumn{2}{|c|}{$42 \pm 6.12$} \\
\hline \multirow{4}{*}{$\begin{array}{l}\text { Weight } \\
\text { (Kg) }\end{array}$} & $\mathrm{CON}$ & $75.48 \pm 6.04$ & $75.38 \pm 5.03$ \\
\hline & ICR & $76.93 \pm 7.43$ & $72.63 \pm 5.53$ \\
\hline & HIIT+ICR & $75.82 \pm 7.14$ & $70.93 \pm 7.10$ \\
\hline & CONT +ICR & $75.39 \pm 6.97$ & $70.69 \pm 7.23$ \\
\hline \multirow{4}{*}{ Lean body mass (Kg) } & $\mathrm{CON}$ & $46.36 \pm 2.67$ & $45.58 \pm 3.43$ \\
\hline & ICR & $46.68 \pm 4.38$ & $43.98 \pm 5.42$ \\
\hline & HIIT+ICR & $46.17 \pm 4.15$ & $46.32 \pm 3.10$ \\
\hline & $\mathrm{CONT}+\mathrm{ICR}$ & $47.18 \pm 4.07$ & $46.93 \pm 5.03$ \\
\hline \multirow{5}{*}{ Body fat (\%) } & $\mathrm{CON}$ & $37.73 \pm 2.45$ & $38.38 \pm 6.63$ \\
\hline & ICR & $38.55 \pm 5.77$ & $34.44 \pm 4.23$ \\
\hline & HIIT+ICR & $36.60 \pm 2.06$ & $32.93 \pm 3.03$ \\
\hline & $\mathrm{CONT}+\mathrm{ICR}$ & $38.35 \pm 2.50$ & $32.34 \pm 2.40$ \\
\hline & $\mathrm{CON}$ & $30.11 \pm 2.85$ & $30.87 \pm 4.55$ \\
\hline \multirow{4}{*}{$\begin{array}{l}\text { Body mass index } \\
\qquad\left(\mathrm{kg} / \mathrm{m}^{2}\right)\end{array}$} & ICR & $31.41 \pm 2.80$ & $28.53 \pm 2.70$ \\
\hline & HIIT+ICR & $30.29 \pm 0.70$ & $26.23 \pm 0.43$ \\
\hline & $\mathrm{CONT}+\mathrm{ICR}$ & $31.91 \pm 3.83$ & $26.73 \pm 3.43$ \\
\hline & $\mathrm{CON}$ & $0.89 \pm 0.04$ & $0.89 \pm 0.03$ \\
\hline \multirow{4}{*}{$\begin{array}{l}\text { Waist to hip } \\
(\mathbf{c m})\end{array}$} & ICR & $0.89 \pm 0.06$ & $0.85 \pm 0.03$ \\
\hline & HIIT+ICR & $0.88 \pm 0.02$ & $0.83 \pm 0.03$ \\
\hline & CONT +ICR & $0.89 \pm 0.05$ & $0.84 \pm 0.04$ \\
\hline & $\mathrm{CON}$ & $1245 \pm 81.34$ & $1250 \pm 82.43$ \\
\hline \multirow{4}{*}{$\begin{array}{c}\text { Basal metabolic rate } \\
\text { (kcal) }\end{array}$} & ICR & $1269.80 \pm 74.21$ & $1280.93 \pm 63.22$ \\
\hline & HIIT+ICR & $1216.63 \pm 77.27$ & $1259.45 \pm 57.43$ \\
\hline & $\mathrm{CONT}+\mathrm{ICR}$ & $1212.70 \pm 63.42$ & $1275.67 \pm 6.43$ \\
\hline & $\mathrm{CON}$ & $1679.83 \pm 54.07$ & $1670.78 \pm 55.98$ \\
\hline \multirow{2}{*}{$\begin{array}{c}\text { Total energy } \\
\text { expenditure (kcal) }\end{array}$} & ICR & $1543.70 \pm 157.02$ & $1565.93 \pm 150.03$ \\
\hline & HIIT+ICR & $1646.72 \pm 88.38$ & $1920.73 \pm 76.23$ \\
\hline \multirow{4}{*}{ Calories intake (kcal) } & CONT +ICR & $1669 \pm 90.24$ & $1900.23 \pm 67.19$ \\
\hline & $\mathrm{CON}$ & $1920 \pm 65.72$ & $1950 \pm 66.34$ \\
\hline & ICR & $2097 \pm 115.97$ & $1630 \pm 120.43$ \\
\hline & HIIT+ICR & $2168.18 \pm 167.73$ & $1865.22 \pm 145.43$ \\
\hline \multirow{5}{*}{$\underset{(\mathrm{kg} / \mathrm{l})}{\mathrm{VO}_{2} \mathrm{max}}$} & CONT $+\mathrm{ICR}$ & $2000 \pm 113.03$ & $1840.54 \pm 110.03$ \\
\hline & $\mathrm{CON}$ & $29.93 \pm 5.10$ & $28.68 \pm 4.60$ \\
\hline & ICR & $32.09 \pm 4.39$ & $29.20 \pm 4.28$ \\
\hline & HIIT+ICR & $33.42 \pm 2.97$ & $39.17 \pm 2.24$ \\
\hline & $\mathrm{CONT}+\mathrm{ICR}$ & $32.16 \pm 7.16$ & $40.24 \pm 4.59$ \\
\hline
\end{tabular}

VO2max: oxygen volume max CON: Control group (n=9) ; ICR: intermittent calorie restriction (n=9) ; HIIT + ICR : high intensity interval training + intermittent calorie restriction $(\mathrm{n}=9)$; CONT + ICR: continuous training + intermittent calorie restriction $(n=9)$

Also, the mean and standard deviation of the studied indicators during 48 hours before and 24 hours after the last training session and caloric restriction in four groups are presented in (Table 3). After the data were normal, statistical analysis was performed. 
Sari-Sarraf, V., Parnian-Khajehdizaj, N., \& Amirsasan, R. (2020). High-intensity interval training and continuous training with intermittent calorie restriction in overweight women: Effect on the inflammation and lipid profile. Spor Bilimleri Araştırmaları Dergisi, 5(2), 230-246.

Table 3. Descriptive information of research variables (mean \pm SD)

\begin{tabular}{|c|c|c|c|}
\hline Variable & Groups & Mean \pm SD $($ pre-test $)$ & Mean \pm SD (post-test) \\
\hline \multirow{4}{*}{$\begin{array}{l}\text { Peripheral blood leukocytes } \\
\text { (mg / dl) }\end{array}$} & $\mathrm{CON}$ & $6.92 \pm 0.93$ & $6.76 \pm 1.08$ \\
\hline & ICR & $6.57 \pm 1.54$ & $6.62 \pm 1.61$ \\
\hline & HIIT+ICR & $7.38 \pm 1.75$ & $6.89 \pm 1.50$ \\
\hline & CONT +ICR & $7.38 \pm 1.27$ & $7.47 \pm 1.34$ \\
\hline \multirow{4}{*}{$\begin{array}{c}\text { CRP } \\
(\mathrm{mg} / \mathrm{dl})\end{array}$} & $\mathrm{CON}$ & $1.88 \pm 0.30$ & $1.96 \pm 0.33$ \\
\hline & ICR & $1.67 \pm 0.56$ & $1.21 \pm 0.60$ \\
\hline & HIIT+ICR & $1.71 \pm 0.49$ & $0.88 \pm 0.30$ \\
\hline & CONT +ICR & $1.80 \pm 0.35$ & $0.87 \pm 0.30$ \\
\hline \multirow{4}{*}{ TC (mg / dl) } & $\mathrm{CON}$ & $196.50 \pm 28.19$ & $226.17 \pm 30.155$ \\
\hline & ICR & $194.8 \pm 38.02$ & $226.20 \pm 37.98$ \\
\hline & HIIT+ICR & $194.72 \pm 20.58$ & $141.90 \pm 12.01$ \\
\hline & CONT +ICR & $196.90 \pm 14 / 65$ & $145.70 \pm 21.63$ \\
\hline \multirow{4}{*}{$\begin{array}{c}\text { LDL } \\
(\mathbf{m g} / \mathbf{d l})\end{array}$} & $\mathrm{CON}$ & $114 \pm 32.47$ & $131.66 \pm 29.72$ \\
\hline & ICR & $118.10 \pm 22.11$ & $113.4 \pm 21.53$ \\
\hline & HIIT+ICR & $120.09 \pm 9.04$ & $85.63 \pm 8.65$ \\
\hline & $\mathrm{CONT}+\mathrm{ICR}$ & $116.90 \pm 20.31$ & $80 / 80 \pm 15.91$ \\
\hline \multirow{4}{*}{$\begin{array}{c}\text { HDL } \\
(\mathbf{m g} / \mathrm{dl})\end{array}$} & $\mathrm{CON}$ & $42.33 \pm 4.22$ & $31 / 50 \pm 4.03$ \\
\hline & ICR & $41.90 \pm 5.21$ & $50 \pm 6.74$ \\
\hline & HIIT+ICR & $37.81 \pm 3.76$ & $61.81 \pm 4.55$ \\
\hline & $\mathrm{CONT}+\mathrm{ICR}$ & $39.70 \pm 4.34$ & $61.10 \pm 3.90$ \\
\hline \multirow{4}{*}{$\begin{array}{l}\text { TRG } \\
\text { (mg/dl) }\end{array}$} & $\mathrm{CON}$ & $208 \pm 56.61$ & $219.16 \pm 57.56$ \\
\hline & ICR & $200.4 \pm 15.86$ & $155.5 \pm 43.49$ \\
\hline & HIIT+ICR & $207.36 \pm 14.65$ & $104.27 \pm 19.06$ \\
\hline & $\mathrm{CONT}+\mathrm{ICR}$ & $205.8 \pm 60.27$ & $98.8 \pm 22.08$ \\
\hline
\end{tabular}

CON: Control group ( $\mathrm{n}=9)$; ICR: intermittent calorie restriction $(\mathrm{n}=9)$; HIIT + ICR: high intensity interval training + intermittent calorie restriction $(\mathrm{n}=9)$; CONT + ICR: continuous training + intermittent calorie restriction $(\mathrm{n}=9)$; CRP: $C$ reactive protein TC: total cholesterol; TRG: triglycerides; HDL: high-density cholesterol; LDL: low-density cholesterol

Maximal Oxygen Uptake: Based on the results in (Table 4), the amount of oxygen at different stages of the measurement was significantly different $\left(\mathrm{F}_{1,33}=48.76 \mathrm{P}=0.01\right)$. Also, the effect of group differences, regardless of the effect of measurement steps, indicates a significant difference in the studied groups $(\mathrm{p}=0.01)$. There was a significant difference between the control group and the caloric restriction group with both the HIIT or continuous training groups $(\mathrm{p}<0.05)$. Despite this, there was no significant difference between the control group and the calorie restriction group and the HIIT group with continuous training (Table 4).

Table 4. The analysis of changes in $\mathrm{VO}_{2} \max , \mathrm{CRP}$, Cholesterol, HDL, LDL, TG, Fat percentage, lean body mass studied groups

\begin{tabular}{|c|c|c|c|c|c|c|}
\hline Variable & The Effect of: & $\begin{array}{c}\text { Sum of } \\
\text { squares }\end{array}$ & $\begin{array}{l}\text { Degrees } \\
\text { of } \\
\text { freedom }\end{array}$ & $\begin{array}{c}\text { Mean } \\
\text { Square }\end{array}$ & $\mathbf{F}$ & Sig \\
\hline \multirow{3}{*}{$\mathrm{VO}_{2} \max$} & measurement phases & 111.51 & 1 & 111.51 & 48.76 & $* 0.01$ \\
\hline & group differences & 411.16 & 3 & 137.05 & 59.93 & $* 0.01$ \\
\hline & measurement phases $\times$ group & 714.84 & 3 & 238.28 & 6.09 & $* 0.02$ \\
\hline \multirow{3}{*}{ CRP } & measurement phases & 4.98 & 1 & 4.98 & 131.09 & $* 0.01$ \\
\hline & group differences & 3.49 & 3 & 1.163 & 3.57 & $* 0.024$ \\
\hline & measurement phases $\times$ group & 2.34 & 3 & 0.78 & 20.51 & $* 0.01$ \\
\hline \multirow{3}{*}{ Cholesterol } & measurement phases & 7338.74 & 1 & 734.74 & 78.42 & $* 0.01$ \\
\hline & group differences & 18349.46 & 3 & 6116.49 & 4.67 & $* 0.08$ \\
\hline & measurement phases $\times$ group & 18108.66 & 3 & 6036.22 & 64.50 & $* 0.01$ \\
\hline
\end{tabular}

$* \mathrm{p}<0.05$ 
Sari-Sarraf, V., Parnian-Khajehdizaj, N., \& Amirsasan, R. (2020). High-intensity interval training and continuous training with intermittent calorie restriction in overweight women: Effect on the inflammation and lipid profile. Spor Bilimleri Araştırmaları Dergisi, 5(2), 230-246.

Table 4 (Continue). The analysis of changes in $\mathrm{VO}_{2} \max$, CRP, Cholesterol, HDL, LDL, TG, Fat percentage, lean body mass studied groups

\begin{tabular}{|c|c|c|c|c|c|c|}
\hline Variable & The Effect of: & $\begin{array}{l}\text { Sum of } \\
\text { squares }\end{array}$ & $\begin{array}{c}\text { Degrees } \\
\text { of } \\
\text { freedom }\end{array}$ & $\begin{array}{c}\text { Mean } \\
\text { Square }\end{array}$ & $\mathbf{F}$ & Sig \\
\hline \multirow{3}{*}{ HDL } & measurement phases & 1989.23 & 1 & 1989.23 & 166.59 & $* 0.01$ \\
\hline & group differences & 1646.12 & 3 & 548.71 & 16.65 & $* 0.01$ \\
\hline & measurement phases $\times$ group & 2840.16 & 3 & 946.72 & 79.29 & $* 0.01$ \\
\hline \multirow{3}{*}{ LDL } & measurement phases & 3623.85 & 1 & 3623.85 & 115.60 & $* 0.01$ \\
\hline & group differences & 6077.95 & 3 & 2025.99 & 2.69 & $* 0.062$ \\
\hline & measurement phases $\times$ group & 7824.93 & 3 & 2608.31 & 83.20 & $* 0.01$ \\
\hline \multirow{3}{*}{ TG } & measurement phases & 64962.21 & 1 & 641962.21 & 64.80 & $* 0.01$ \\
\hline & group differences & 34745.21 & 3 & 11581.74 & 3.75 & $* 0.02$ \\
\hline & measurement phases $\times$ group & 35781.47 & 3 & 11927.15 & 11.90 & $* 0.01$ \\
\hline \multirow{4}{*}{ Fat percentage } & measurement phases & 319.01 & 1 & 319.01 & 116.45 & $* 0.01$ \\
\hline & group differences & 365.20 & 3 & 121.74 & 4.22 & $* 0.012$ \\
\hline & measurement phases $\times$ group & 468.19 & 3 & 156.06 & 56.98 & $* 0.01$ \\
\hline & measurement phases & 7.29 & 1 & 7.29 & 6.69 & $* 0.014$ \\
\hline \multirow{2}{*}{$\begin{array}{l}\text { Lean body } \\
\text { mass }\end{array}$} & group differences & 66.47 & 3 & 22.15 & 0.738 & 0.537 \\
\hline & measurement phases $\times$ group & 55.88 & 3 & 18.63 & 17.13 & $* 0.01$ \\
\hline
\end{tabular}

$* \mathrm{p}<0.05$

Inflammatory indicators: In the index of peripheral blood leukocytes of overweight women, the effect of measurement steps on interaction with the studied groups and the effect of group differences are not significant $(\mathrm{p}>0.05)$. C-reactive protein was significantly different at different stages of measurement $\left(\mathrm{F}_{1,33}=131.09 \mathrm{p}=0.01\right)$. In the index CRP, continuous and HIIT training in the post-test phase compared to the pre-test in the study groups without considering the research groups, caused a significant difference. Also, the effect of group differences regardless of the effect of measurement steps showed a significant difference in the studied groups $\left(\mathrm{F}_{3,33}=3.57 \mathrm{p}=0.024\right)$. There was also a difference between the groups studied and the effect of the measurement steps $\left(\mathrm{F}_{3,33}=20.51 \mathrm{p}=0.01\right)$ (Table 4). There is a significant difference between HIIT and continuous training groups with calorie restriction and control group $(\mathrm{p}<0.05)($ Table 4$)$.

Lipid profile: Eight-week combination of high intensity interval training (HIIT) and continuous training with ICR caused significant differences in post-test compared to pre-test in terms of total cholesterol, triglyceride, HDL and LDL indices ( $\mathrm{p}<0.05)$ (Table 4). Also, there was a significant difference between cholesterol, HDL and triglyceride indexes in training groups with caloric restriction and control group $(\mathrm{p}<0.05)$ (Table 5). On the other hand, there was a significant difference between the calorie restriction group and the control group in the HDL index.

Taking body fat percentage and lean body mass into account, we also see a significant difference in post-test compared to pre-test $(\mathrm{p}<0.05)$ (Table 4)., and There was a significant difference between HIIT and continuous training groups with calorie restriction and control group ( $p<0.05$ ) (Table 5). There was no significant difference between the study groups in the lean body mass index. 
Sari-Sarraf, V., Parnian-Khajehdizaj, N., \& Amirsasan, R. (2020). High-intensity interval training and continuous training with intermittent calorie restriction in overweight women: Effect on the inflammation and lipid profile. Spor Bilimleri Araştırmaları Dergisi, 5(2), 230-246.

Table 5. Post-test to pre-test ratio of $\mathrm{VO}_{2} \max , \mathrm{CRP}$, Cholesterol, HDL,TG,Fat percentage in the studied groups

\begin{tabular}{|c|c|c|c|c|}
\hline $\begin{array}{l}\text { Post-test to pre- } \\
\text { test ratio of: }\end{array}$ & & & $\begin{array}{c}\text { Mean } \\
\text { differences }\end{array}$ & Sig \\
\hline \multirow{7}{*}{$\mathrm{VO}_{2} \max$} & \multirow{3}{*}{$\mathrm{CON}$} & ICR & 1.34 & 1.000 \\
\hline & & HIIT+ICR & 7.19 & $* 0.018$ \\
\hline & & CONT +ICR & 6.90 & $* 0.029$ \\
\hline & \multirow{2}{*}{ ICR } & HIIT+ICR & 5.85 & $* 0.029$ \\
\hline & & CONT +ICR & 5.55 & $* 0.050$ \\
\hline & CONT +ICR & HIIT+ICR & 0.29 & 1.000 \\
\hline & & ICR & 0.49 & 0.157 \\
\hline \multirow{3}{*}{ CRP } & \multirow{3}{*}{$\mathrm{CON}$} & HIIT+ICR & 0.63 & $* 0.026$ \\
\hline & & CONT+ICR & 0.59 & $* 0.047$ \\
\hline & & ICR & 20.33 & 0.801 \\
\hline \multirow{3}{*}{ Cholestrol } & \multirow{3}{*}{$\mathrm{CON}$} & HIIT+ICR & 43.015 & $* 0.014$ \\
\hline & & CONT+ICR & 40.03 & $* 0.028$ \\
\hline & & ICR & 9.04 & $* 0.01$ \\
\hline \multirow{3}{*}{ HDL } & \multirow{3}{*}{$\mathrm{CON}$} & HIIT+ICR & 12.90 & $* 0.01$ \\
\hline & & CONT+ICR & 13.48 & $* 0.01$ \\
\hline & & ICR & 35.64 & 0.531 \\
\hline \multirow{3}{*}{ TG } & \multirow{3}{*}{$\mathrm{CON}$} & HIIT+ICR & 57.77 & $* 0.040$ \\
\hline & & CONT +ICR & 61.29 & $* 0.029$ \\
\hline & & ICR & 2.55 & 1.000 \\
\hline \multirow{2}{*}{ Fat Percentage } & \multirow{2}{*}{$\mathrm{CON}$} & HIIT+ICR & 5.45 & $* 0.046$ \\
\hline & & CONT+ICR & 6.04 & $* 0.025$ \\
\hline
\end{tabular}

Method followed by Bonferroni's post-hoc was used. * p<0.05

\section{DISCUSSION and CONCLUSION}

This study compared the effect of HIIT and continuous training and synergic combination of calorie restriction on inactive women. Therefore, we aimed at determining the effect of eight weeks of intermittent calorie restriction combined with HIIT and continuous training on inflammatory and lipid profile indexes on overweight women.

\section{$\mathrm{VO}_{2} \mathbf{m a x}$}

The results of the current study clearly indicated that HIIT and continuous training along with calorie restriction had a significant effect on increasing $\mathrm{VO}_{2 \max }$ of overweight women. Findings of the present study are consistent with those of Asternio et al. (2017), Niloufar Mosafa et al. (2018), and Liebardi et al., (2012). As Astnerio et al. (2017) showed, ten sessions of intermittent training with eight to ten repetitions of 60 seconds of cycling with 90 to 110 percent of maximum mobile output power, 75 seconds of active rest between repetitions remarkably increased VO2max in active men and women (Astorino et al., 2017). Niloufar Mosafa et al., (2018) also examined the effect of eight weeks of intermittent exercise on (three sessions per week and three 10-second interval sessions with 30-second intervals, followed by three 30 second rotational intervals with 20-second rest intervals) overweight elderly women and stated an increase in $\mathrm{VO}_{2 \max }$ (Mosaffa \& Abedi, 2018). Also, Libardi et al. (2012), whose outcomes were consistent with the results of the present study, showed that 16 weeks of continuous exercise with and without calorie restriction in healthy men significantly increased their 
Sari-Sarraf, V., Parnian-Khajehdizaj, N., \& Amirsasan, R. (2020). High-intensity interval training and continuous training with intermittent calorie restriction in overweight women: Effect on the inflammation and lipid profile. Spor Bilimleri Araştırmaları Dergisi, 5(2), 230-246.

VO2max (Libardi et al., 2012). This study showed that there were no meaningful differences between intermittent training group along with calorie restriction and continuous training group along with calorie restriction on the amount of $\mathrm{VO}_{2 \max }$. Although both intermittent and continuous training improved $\mathrm{VO}_{2 \max }$, this increase would only happen if there was a small beneficiary effect on continuous training group rather than intermittent; this was confirmed by the results of the previous studies (Lo., 2011; Trapp et al., 2008).

\section{Lipid Profile}

The results indicated that HIIT and continuous exercise combined with caloric restriction caused fundamental differences compared to the control group in the lipid profiles of the subjects. In contrast, there was no difference between the training groups. According to a study by Tartibian et al. (2016), 12 weeks and four sessions of intermittent exercise on a workbench wheel with a maximum intensity of $70 \%$ caused a decrease in total cholesterol, LDL-C and triglycerides and conversely, an increase in HDL (Tartibian et al., 2016). In their study of inactive men, Altna et al. (2006) reported that regular, continuous exercise on the rotator cuff for 4 weeks, 5 sessions per week with a $75 \%$ maximum heart rate reduced total cholesterol and LDL although there was a significant increase in HDL (Altena et al.,2006).

However, the mechanism of the effectiveness of intermittent and continuous exercise on improving lipid profile is related to the enzymatic process involved in lipid metabolism (Valle et al., 2010). In this regard, Sougira et al. Showed that regular exercise is associated with increased activity of lipoprotein lipase (LPL) and lysitin cholesterol enzyme cholesterol (LCAT) enzymes, which reduces TC, TG, LDL and increases HDL (Sugiura et al.,2002). Researchers also concluded that the mechanism involved in positive changes in lipid profiles due to caloric restriction was an increase in LPL levels and a consequent increase in triglyceride clearance. An increase in the catabolism of triglyceride-rich lipoproteins is caused when LPL transfers unsaturated cholesterol, apoprotein, and phospholipids to adult HDL cholesterol (Moghadamnia et al.,2015). In addition, Wang et al. (2010) examined the effects of 3-day calorie restriction on fasting blood lipids in hyperlipidemia caused by a 5-week high-fat diet in an animal model and reported a reduction in triglyceride, total cholesterol and LDL levels( Wang et al., 2010). Mou et al. (2015) examined the effects of various calorie restrictive diets (20, 50 and $70 \%$ of daily energy requirement) on cardiac metabolic risk factors in obese and overweight women and showed a substantial drop in total cholesterol by $7 \%$ in the first group and $8 \%$ in the third group and LDL levels by $14 \%$ in the first group and $13 \%$ in the third group. However, no significant change was observed in the $50 \%$ of the group in cholesterol and LDL levels (Mou et al., 2015).

In this study, there was no significant difference between HIIT and continuous exercise with caloric restriction at lipid profile (LDL, HDL, triglyceride and cholesterol) levels. Bourdieu et al. (2007) studied the effect of different types of exercises on lipid profiles and concluded that all types of sports, including resistance, aerobic and combination, have the same effects on lipids (Boardley et al., 2007). Contrary to current findings, Thomas et al. (1985) performed 11 weeks of continuous aerobic activity ( 5 mile running) and intermittent training (4 minutes of running with a work-to-rest ratio of 1: 1 and 2 minutes of running with a work-to-rest ratio 1.2:1:1). Although during the $11^{\text {th }}$ weeks, they performed 3 times a week for one hour, they did 
Sari-Sarraf, V., Parnian-Khajehdizaj, N., \& Amirsasan, R. (2020). High-intensity interval training and continuous training with intermittent calorie restriction in overweight women: Effect on the inflammation and lipid profile. Spor Bilimleri Araştırmaları Dergisi, 5(2), 230-246.

not show any change in lipid profile (Thomas et al.,1985). The reason for this contradiction can be found in the intensity, duration, conditions and physical fitness of the subjects.

\section{Inflammatory Indices}

The findings indicated that there was no difference in the leukocyte index of peripheral blood between any of the groups studied. But in the reactive protein index, there was a difference between the training groups and the caloric restriction with the other groups. Also, in this index (CRP), there was no difference between HIIT and continuous exercise groups with caloric restriction. These results with the results of studies, Moghaddam et al. (2017), Martin et al. (2010) and Bahrami et al. (2011) are aligned

Moghaddam et al. (2015) stated that four weeks (three sessions per week) of intense interval training with Rast test (6 repetitions of running with maximum speed at a distance of 35 meters and active rest of 10 seconds between repetitions) and alternating group with Wingate test on the working wheel It significantly reduced CRP in both training groups in overweight women (Shariatzadeh et al.,2017). Martin et al. (2010) stated in their study, performing periodic aerobic exercises for 16 and 32 weeks reduces HS-CRP by 10 and 15 percent, respectively, along with increasing strength and reducing body fat (Martins et al.,2010). Bahrami et al. (2011) studied the effect of 12 weeks of aerobic exercise ( 3 sessions per week and each session for 60 minutes with an intensity of 65 to $80 \%$ of maximum heart rate) with a limit of 500 calories and a calorie restriction group (500 calories per day). They examined obese women. Their results showed that in the aerobic exercise group with calorie restriction, a significant decrease was observed in CRP, but in the caloric restriction group, there was no significant decrease in CRP level (Bahrami et al., 2011).

Limited studies have shown that physical activity by reducing fat and leptin and increasing adiponectin and insulin sensitivity reduces interleukin 6 (IL-6) and the tumor necrosis factor alpha (TNF- $\alpha$ ) and thus reduces Becomes CRP. Evidence suggests that increased nitric oxide from endothelial blood vessels and improved endothelial wall function reduces systemic and local inflammation, resulting in decreased production of inflammatory cytokines from the smooth muscles of the endothelial wall (Nicklas et al.,2008). On the other hand, reducing the CRP concentration in subjects can be attributed to other factors such as improving factors related to body composition such as weight loss, fat loss and WHR, increasing vitamin absorption in the intestine, increasing enzymatic activity and nitric oxide (NO) production, which leads to Reduces CRP. On the other hand, it is possible that exercise can reduce inflammation by reducing the production of inflammatory cytokines from adipose tissue and increasing insulin sensitivity and weight loss. These can be effective in preventing cardiovascular disease (Nicklas et al., 2008; e Silva \& da Mota, 2014). Contrary to current research, Havanloo et al. (2011) stated that 2 weeks of intermittent training ( 3 sessions per week, including 4 to 6 weeks of Wingate test with maximum power and 4 minutes of recovery between periods) And continuous exercise ( 3 sessions of 90 to 120 minutes of activity per week with an intensity of $65 \%$ of maximum oxygen consumption on the carousel wheel) showed that it had no effect on the C-reactive protein and the number of blood leukocytes (Havanloo et al., 2011). 
Sari-Sarraf, V., Parnian-Khajehdizaj, N., \& Amirsasan, R. (2020). High-intensity interval training and continuous training with intermittent calorie restriction in overweight women: Effect on the inflammation and lipid profile. Spor Bilimleri Araştırmaları Dergisi, 5(2), 230-246.

According to the findings of the present study, performing 8 weeks of HIIT and continuous exercise with caloric restriction significantly reduced the fat percentage of subjects. The findings of this study are consistent with the results of Behrad et al. (2016), Dupuyt et al. (2020). Behrad et al. (2016) who showed that performing 8 weeks of intermittent exercise (3 sessions per week and one session per hour) with an intensity of 85 to $95 \%$ of maximum heart rate significantly dropped body fat percentage, body weight and WHR of overweight women. Despite this, it did not affect the fat-free mass of the subjects( Behrad et al.,2016). Dupuyt et al. (2020) worked on the effect of moderate-intensity exercise and intense periodic training with and without resistance training on changing the physical composition of postmenopausal women and stated that three months of moderate-intensity continuous training and intense continuous training with and without exercise Resistance increases the oxidation of fatty acids and reduces body fat mass by increasing mitochondrial enzymes (citrate synthase, betahydroxyacyl coenzyme A and pyruvate dehydrogenase) on the one hand and increasing the number of fatty acid transmitters (FAT / FABPpm.CD36) on the other hand. HIIT workouts, compared to other workouts, effectively reduce most of visceral fat in abdominal (Dupuit et al.,2020) by increasing mitochondrial enzymes and fatty acid transmitters in the short term as well as augmenting fat oxidation. Also, the findings of Kendrew et al. (2009) and Kazemzadeh et al. (2017) in contrast to the present study indicated a significant decrease in fat percentage. Kendrew Study Group examined the effect of 12 weeks of intermittent exercise in 3 sessions per week with an intensity of 80 to $90 \%$ of the maximum heart rate with a bicycle (6 to 10 seconds of cycling with active rest) on overweight women and reported that the exercise protocol had no effect on body fat percentage, body weight and body mass index (Kendrew, 2009). In line with this research, Ghaledari and colleagues (2016) studied 20 overweight volunteer men. The subjects were in two groups of 12 weeks of aerobic exercise including 3 sessions per week for one hour with 60 to $65 \%$ maximum oxygen consumption with caloric restriction $(350 \mathrm{kcal})$ for one group and calorie restriction alone $(500 \mathrm{kcal})$ for the other group. Their results showed that the fat percentage decreased significantly only in the combined exercise and calorie restriction group. Also, lean body mass did not differ in any of the groups (Ghaledari \& Banaee, 2016). However, in the present study, there was no difference between the two groups of periodic and continuous exercise with caloric restriction in the fat percentage index of the subjects. These results are consistent with the studies of Zhang et al. (2017), Foroutan et al. (2018) and Vatani et al. (2017) (Zhang et al.,2017; Sheikholeslami-vatani et al.,2018; Foroutan et al., 2018).

\section{Conclusion}

Based on the findings of the study, it can be concluded that regular exercise and regular exercise with the application of intermittent calorie restriction are likely to prevent obesity, cardiovascular disease and physical illness by reducing the levels of C-reactive protein (CRP) and positive changes in body composition indicators and lipid profile. Therefore, considering the precautionary aspects and individual characteristics, overweight and obese people who are at risk can be recommended to use both intermittent exercise and continuous exercise with calorie restriction to prevent or reduce the complications of metabolic syndrome. Due to the lack of measurement of intracellular and genetic pathways in the present study, it is suggested that the present research be performed on effective intracellular pathways. It can also be suggested that a similar study be performed on obese and overweight men to examine the effect of gender in the study. On the other hand, another study can be done at the same time as women 
Sari-Sarraf, V., Parnian-Khajehdizaj, N., \& Amirsasan, R. (2020). High-intensity interval training and continuous training with intermittent calorie restriction in overweight women: Effect on the inflammation and lipid profile. Spor Bilimleri Araştırmaları Dergisi, 5(2), 230-246.

start menstruating. And the final suggestion is to do a similar study with a $20 \%$ calorie limit (10\% fat and $10 \%$ carbohydrate).

\section{Limitations}

The effect of genetic and personality differences, possible injuries, possible stress, the amount of sleep and rest around the clock, economic, social, marital and occupational status of the subjects, tissue damage that may not have been reported by the subjects. possible use of fat burning supplements and anti-inflammatory drugs such as ibuprofen, etc. without reporting by the subjects.

\section{REFERENCES}

Allen, N. G., Higham, S. M., Mendham, A. E., Kastelein, T. E., Larsen, P. S. \& Duffield, R. (2017). The effect of high-intensity aerobic interval training on markers of systemic inflammation in sedentary populations. European Journal of Applied Physiology, 117(6), 1249-1256. DOI: 10.1007/s00421-0173613-1.

Altena, T. S., Michaelson, J. L., Ball, S. D., Guilford, B. L. \& Thomas, T. R. (2006). Lipoprotein subfraction changes after continuous or intermittent exercise training. Medicine and science in sports and exercise, 38(2), 367-372. DOI: 10.1249/01.mss.0000185088.33669.fd.

Astorino, T. A., Edmunds, R. M., Clark, A., King, L., Gallant, R. A., Namm, S., ... \& Wood, K. M. (2017). Highintensity interval training increases cardiac output and VO2max. Med Sci Sports Exerc, 49(2), 265-273. DOI: 10.1249/MSS.0000000000001099.

Bahrami, A. \& Saremi, A. (2011). Effect of caloric restriction with or without aerobic training on body composition, blood lipid profile, insulin resistance, and inflammatory marker in middle-age obese /overweight men. J Arak Uni Med Sci, 14(3), 11-19.

Barranco, P., Delgado, J., Gallego, L. T., Bobolea, I., Pedrosa, M., García, D. L. A. \& Quirce, S. (2012). Asthma, obesity and diet. Nutricion hospitalaria, 27(1), 138-145.

Behrad, A., Askari, R. \& Hamednia, M.R. (2016). The effect of high intensity interval training and circuit resistance training on respiratory function and body composition in overweight females. Journal of Exercise Physiology and Physical Activity, 4(7), 89-101.

Boardley, D., Fahlman, M., Topp, R., Morgan, A. L. \& McNevin, N. (2007). The impact of exercise training on blood lipids in older adults. The American journal of geriatric cardiology, 16(1), 30-35.DOI: 10.1111/j.1076-7460.2007.05353.x.

Brown, W. M., Davison, G. W., McClean, C. M. \& Murphy, M. H. (2015). A systematic review of the acute effects of exercise on immune and inflammatory indices in untrained adults. Sports medicineopen, 1(35), 1-10. DOI: 10.1186/s40798-015-0032-x.

Campbell, K. L., Campbell, P. T., Ulrich, C. M., Wener, M., Alfano, C. M., Foster-Schubert, K., ... \& McTiernan, A. (2008). No reduction in C-reactive protein following a 12-month randomized controlled trial of exercise in men and women. Cancer Epidemiology and Prevention Biomarkers, 17(7), 1714-1718. DOI: 10.1158/1055-9965.EPI-08-0088.

Davis, R. A., Halbrooks, J. E., Watkins, E. E., Fisher, G., Hunter, G. R., Nagy, T. R. \& Plaisance, E. P. (2017). High-intensity interval training and calorie restriction promote remodeling of glucose and lipid metabolism in diet-induced obesity. American Journal of Physiology-Endocrinology and Metabolism, 313(2), E243-E256. DOI: 10.1152/ajpendo.00445.2016.

Dossus, L., Rinaldi, S., Becker, S., Lukanova, A., Tjonneland, A., Olsen, A., ... \& Clavel-Chapelon, F. (2010). Obesity, inflammatory markers, and endometrial cancer risk: a prospective case-control study. Endocrine-related cancer, 17(4), 1007. DOI: 10.1677/ERC-10-0053. 
Sari-Sarraf, V., Parnian-Khajehdizaj, N., \& Amirsasan, R. (2020). High-intensity interval training and continuous training with intermittent calorie restriction in overweight women: Effect on the inflammation and lipid profile. Spor Bilimleri Araştırmaları Dergisi, 5(2), 230-246.

Dupuit, M., Rance, M., Morel, C., Bouillon, P., Pereira, B., Bonnet, A., ... \& Boisseau, N. (2020). Moderateintensity continuous training or high-intensity interval training with or without resistance training for altering body composition in postmenopausal women. Medicine and Science in Sports and Exercise, 52(3), 736-745. DOI: 10.1249/mss.0000000000002162.

e Silva, A. D. S. \& da Mota, M. P. G. (2014). Effects of physical activity and training programs on plasma homocysteine levels: A Systematic review. Amino acids, 46(8), 1795-1804. DOI: 10.1007/s00726-0141741-z.

Ferguson, B. (2014). ACSM's guidelines for exercise testing and prescription. 9th Ed. The Journal of the Canadian Chiropractic Association, 58(3), 328-329.

Foroutan, Y., Daneshyar, S., Tadibi, V. \& Behpoor, N. (2018). Comparison of different concurrent protocols of lipid profile, insulin resistance index and some white adipose tissue hormones. Fats inactive men overweight. The Journal of Urmia University of Medical Sciences, 28(12), 805-816.

Friedewald, W. T., Levy, R. I. \& Fredrickson, D. S. (1972). Estimation of the concentration of low-density lipoprotein cholesterol in plasma, without use of the preparative ultracentrifuge. Clinical chemistry, 18(6), 499-502. DOI: 10.1093/clinchem/18.6.499.

Ghaledari, M. \& Banee, A. (2016). Effect of 12 weeks of aerobic exercise with maximum severity of fat oxidation and calorie restriction on plasma abelin levels 36 and insulin resistance in overweight men. Sport Physiology (Research on Sport Science), 8(32), 153-168.

Gibala, M. J., Little, J. P., MacDonald, M. J. \& Hawley, J. A. (2012). Physiological adaptations to low-volume, high-intensity interval training in health and disease. The Journal of physiology, 590(5), 1077-1084. DOI: 10.1113/jphysiol.2011.224725.

Gibson, A. L., Wagner, D. \& Heyward, V. (2018). Advanced Fitness Assessment and Exercise Prescription. 8 Edition. Champaign II: Human kinetics.

Gist, N. H., Fedewa, M. V., Dishman, R. K. \& Cureton, K. J. (2014). Sprint interval training effects on aerobic capacity: a systematic review and meta-analysis. Sports medicine, 44(2), 269-279. DOI:10.1007/s40279013-0115-0.

Havanloo, F., Arefi-Rad, T., Ahmadizad, S. \& Hedayati, M. (2011). The effect of 2 types of speed-periodic and endurance-continuous training with different intensities and volumes on the level of inflammatory markers. Iranian Journal of Diabetes and Metabolism, 11(2),193-202.

Housh, T. J., Housh, D. J. \& DeVries, H. A. (2017). Applied exercise and sport physiology, With Labs. New York: Taylor \& Francis.

Imayama, I., Ulrich, C. M., Alfano, C. M., Wang, C., Xiao, L., Wener, M. H., ... \& Mason, C. E. (2012). Effects of a caloric restriction weight loss diet and exercise on inflammatory biomarkers in overweight/obese postmenopausal women: a randomized controlled trial. Cancer research, 72(9), 2314-2326.DOI: 10.1158/0008-5472.CAN-11-3092.

Jackson, A. S. \& Pollock, M. L. (1985). Practical assessment of body composition. The Physician and Sportsmedicine, 13(5), 76-90. DOI: 10.1080/00913847.1985.11708790.

Janghorbani, M., Amini, M., Willett, WC., Gouya, MM., Delavari, A., Alikhani, S. \& Mahdavi, A. (2007). First nationwide survey of prevalence of overweight, underweight, and abdominal obesity in Iranian adults. Obesity, 15(11), 2797-808.

Johnson, N. A., Sachinwalla, T., Walton, D. W., Smith, K., Armstrong, A., Thompson, M. W. \& George, J. (2009). Aerobic exercise training reduces hepatic and visceral lipids in obese individuals without weight loss. Hepatology, 50(4), 1105-1112. DOI: 10.1002/hep.23129.

Kazemzadeh, Y., Banaeefar, A., Shirvani, H. \& Gharaat,A . (2017). The effect of high intensity interval training HIIT on body composition, lipid profile and insulin sensitivity in overweight young men. Physiology of Exercise and Physical Activity, 9(2), 1385-1394. 
Sari-Sarraf, V., Parnian-Khajehdizaj, N., \& Amirsasan, R. (2020). High-intensity interval training and continuous training with intermittent calorie restriction in overweight women: Effect on the inflammation and lipid profile. Spor Bilimleri Araştırmaları Dergisi, 5(2), 230-246.

Kendrew, J. (2009). The Encylopedia of Molecular Biology. John Wiley \& Sons.

Libardi, C. A., De Souza, G. V., Cavaglieri, C. R., Madruga, V. A. \& Chacon-Mikahil, M. P. T. (2012). Effect of resistance, endurance, and concurrent training on TNF- $\alpha$, IL-6, and CRP. Medicine \& Science in Sports \& Exercise, 44(1), 50-56. DOI: 10.1249/MSS.0b013e318229d2e9.

Lo, M. S., Lin, L. L., Yao, W. J. \& Ma, M. C. (2011). Training and detraining effects of the resistance vs. endurance program on body composition, body size, and physical performance in young men. The Journal of Strength \& Conditioning Research, 25(8), 2246-2254. DOI:10.1519/JSC.0b013e3181e8a4be.

Margolis, K. L., Rodabough, R. J., Thomson, C. A., Lopez, A. M. \& McTiernan, A. (2007). Prospective study of leukocyte count as a predictor of incident breast, colorectal, endometrial, and lung cancer and mortality in postmenopausal women. Archives of internal medicine, 167(17), 1837-1844. DOI:10.1001/archinte.167.17.1837.

Mou, Z., Hyde, T. M., Lipska, B. K., Martinowich, K., Wei, P., Ong, C. J., ... \& Lai, C. (2015). Human obesity associated with an intronic SNP in the brain-derived neurotrophic factor locus. Cell reports, 13(6), 10731080. DOI: 10.1016/j.celrep.2015.09.065.

Mogharnasi, M., Gaeini, A., Javadi, E., Kordi, M., Ravasi, A. \& Sheikholeslami Vatani, D. (2009). The effect of endurance training on inflammatory biomarkers and lipid profiles in wistar rats. World Journal of Sport Sciences (WJSS), 2(2), 82-88.

Martins, R. A., Veríssimo, M. T., e Silva, M. J. C., Cumming, S. P. \& Teixeira, A. M. (2010). Effects of aerobic and strength-based training on metabolic health indicators in older adults. Lipids in Health and disease, 9(1), 1-6.

Moghadamnia, AA., Hakiminia, S., Baradaran, M., Kazemi, S. \& Ashraf-pour, M. (2015). Vitamin D Improves Learning and Memory Impairment in Streptozotocin-Induced Diabetic Mice. Archives of Iranian Medicine (AIM), 18(6), 362-366.

Mosaffa, N. \& Abedi, B. (2018). The Effect of Eight Week Interval training on The Serum VCAM-1 and PAI-1 in Obesity Women. Journal of Sport Biosciences, 10(2),193-206. DOI: 10.22059/jsb.2018.227583.1148.

Nicklas, B. J., Hsu, F. C., Brinkley, T. J., Church, T., Goodpaster, B. H., Kritchevsky, S. B. \& Pahor, M. (2008). Exercise training and plasma C-reactive protein and interleukin-6 in elderly people. Journal of the American Geriatrics Society, 56(11), 2045-2052. DOI: 10.1111/j.1532-5415.2008.01994.x.

Perry, C. G., Heigenhauser, G. J., Bonen, A. \& Spriet, L. L. (2008). High-intensity aerobic interval training increases fat and carbohydrate metabolic capacities in human skeletal muscle. Applied Physiology, Nutrition, and Metabolism, 33(6), 1112-1123. DOI: 10.1139/H08-097.

Pihl, E., Zilmer, K., Kullisaar, T., Kairane, C., Pulges, A. \& Zilmer, M. (2003). High-sensitive C-reactive protein level and oxidative stress-related status in former athletes in relation to traditional cardiovascular risk factors. Atherosclerosis, 171(2), 321-326. DOI:10.1016/j.atherosclerosis.2003.08.015.

Rawson, E. S., Freedson, P. S., Osganian, S. K., Matthews, C. E., Reed, G. \& Ockene, I. S. (2003). Body mass index, but not physical activity, is associated with C-reactive protein. Medicine and science in sports and exercise, 35(7),1160-1166. DOI: 10.1249/01.MSS.0000074565.79230.AB.

Ricci-Cabello, I., Olalla Herrera, M. \& Artacho, R. (2012). Possible role of milk-derived bioactive peptides in the treatment and prevention of metabolic syndrome. Nutrition reviews, 70(4), 241-255. DOI:10.1111/j.1753-4887.2011.00448.x.

Sheikholeslami-vatani, D. \& Ebrahimi, A. (2018). The Effect of Moderate-Intensity Continuous Training Vs. High-Intensity Interval Training on Visceral and Subcutaneous Fats in Obese Women. Journal of Rafsanjan University of Medical Sciences (JRUMS), 16(11),999-1012.

Shariatzadeh, M., Moghadam, Z., Maleki, L., Keshavarz, E. \& Hedayati, M. (2017). Short-Term Effect of Two Types of High-Intensity Interval Training on Plasma Level of TNF- $\alpha$, IL-6, CRP and Lipid Profile of Overweight Women. Journal of Sport Biosciences, 9(2), 195-207. DOI:10.22059/jsb.2017.128575.963. 
Sari-Sarraf, V., Parnian-Khajehdizaj, N., \& Amirsasan, R. (2020). High-intensity interval training and continuous training with intermittent calorie restriction in overweight women: Effect on the inflammation and lipid profile. Spor Bilimleri Araştırmaları Dergisi, 5(2), 230-246.

e Silva, A. D. S. \& da Mota, M. P. G. (2014). Effects of physical activity and training programs on plasma homocysteine levels: a systematic review. Amino acids, 46(8), 1795-1804. DOI: 10.1007/s00726-014$1741-\mathrm{z}$

Sugiura, H., Sugiura, H., Kajima, K., Mirbod, S. M., Iwata, H. \& Matsuoka, T. (2002). Effects of long-term moderate exercise and increase in number of daily steps on serum lipids in women: randomised controlled trial [ISRCTN21921919]. BMC Women's Health, 2(1), 34-42. DOI: 10.1186/1472-6874-2-3.

Tartibian, B., Sharifi, H. \& Ebrahimi-Turkmani, B. (2016). The effect of 12-week high-intensity interval training (HIIT) on lung function, serum leptin level and lipid profiles in inactive obese men. Medical Journal of Tabriz University of Medical Sciences and Health Services, 24(4),23-30.

Thomas, T. R., Adeniran, S. B., Iltis, P. W., Aquiar, C. A. \& Albers, J. J. (1985). Effects of interval and continuous running on HDL-cholesterol, apoproteins A-1 and B, and LCAT. Canadian Journal of Applied Sport Sciences. Journal Canadien des Sciences Appliquees au Sport, 10(1), 52-59.

Trapp, E. G., Chisholm, D. J., Freund, J. \& Boutcher, S. H. (2008). The effects of high-intensity intermittent exercise training on fat loss and fasting insulin levels of young women. International journal of obesity, 32(4), 684-691.DOI: 10.1038/sj.ijo.0803781.

Valle, V. S. D., Mello, D. B. D., Fortes, M. D. S. R., Dantas, E. H. M. \& Mattos, M. A. D. (2010). Effect of diet and indoor cycling on body composition and serum lipid. Arquivos brasileiros de cardiologia, 95(2), 173-178.

Wang, C., Bomberg, E., Billington, C. J., Levine, A. S. \& Kotz, C. M. (2010). Brain-derived neurotrophic factor (BDNF) in the hypothalamic ventromedial nucleus increases energy expenditure. Brain research, 1336, 66-77.DOI: 10.1016/j.brainres.2010.04.013.

Weiss, E. P., Albert, S. G., Reeds, D. N., Kress, K. S., McDaniel, J. L., Klein, S. \& Villareal, D. T. (2016). Effects of matched weight loss from calorie restriction, exercise, or both on cardiovascular disease risk factors: a randomized intervention trial. The American journal of clinical nutrition, 104(3), 576-586. DOI: 10.3945/ajcn.116.131391.

Williams, P. T., Krauss, R. M., Stefanick, M. L., Vranizan, K. M. \& Wood, P. D. (1994). Effects of low-fat diet, calorie restriction, and running on lipoprotein subfraction concentrations in moderately overweight men. Metabolism, 43(5), 655-663.DOI: 10.1016/0026-0495(94)90210-0.

Zhang, H., Tong, T. K., Qiu, W., Zhang, X., Zhou, S., Liu, Y. \& He, Y. (2017). Comparable effects of highintensity interval training and prolonged continuous exercise training on abdominal visceral fat reduction in obese young women. Journal of diabetes research, 2017, 1-9. DOI:10.1155/2017/5071740.

Ziccardi, P., Nappo, F., Giugliano, G., Esposito, K., Marfella, R., Cioffi, M., ... \& Giugliano, D. (2002). Reduction of inflammatory cytokine concentrations and improvement of endothelial functions in obese women after weight loss over one year. Circulation, 105(7), 804-809. DOI: 10.1161/hc0702.104279.

Except where otherwise noted, this paper is licensed under a Creative Commons Attribution 4.0 International license. 